\title{
Army "New Standards" Personnel: Effect of Remedial Literacy Training on Performance in Military Service
}

Allan H. Fisher, Jr.

HumRRO Division No. 7 (Social Science)

Alexandria, Virginia

HUMAN RESOURCES RESEARCH ORGANIZATION

Prepared for

Manpower Development Division,

Air Force Human Resources Laboratory, Air Force Systems Command Alexandria, Virginia

Originally published as AFHRL-TR-71-13 